\title{
Iron Administration Affects Cardiac Calcium Channel Expression in Mice: The Role of Cardiac Calcium Channel Expression in The Heart of Iron Overload Mice Model
}

\author{
Mas Rizky Anggun Adipurna Syamsunarno ${ }^{1,2,3 *}$, Alif Bagus Rakhimullah ${ }^{1,4}$, Uni Gamayani ${ }^{5,6}$, \\ Masahiko Kurabayasi ${ }^{7,8}$, Tatsuya Iso ${ }^{7,8}$, Ratu Safitri ${ }^{9}$, Ramdan Panigoro, ${ }^{1,2}$ \\ ${ }^{1}$ Biochemistry Division, Department Biomedical Science, Faculty of Medicine, Universitas Padjadjaran, Jl. Raya Bandung Sumedang No. KM 21, \\ Jatinangor 45363, Indonesia \\ ${ }^{2}$ Central Laboratory, Universitas Padjadjaran, Universitas Padjadjaran, Jl. Raya Bandung Sumedang No.KM 21, Jatinangor 45363, Indonesia \\ ${ }^{3}$ Department of Biology, Faculty of Mathematics and Natural Science, Universitas Padjadjaran, Universitas Padjadjaran, J1. Raya Bandung Sumedang \\ No.KM 21, Jatinangor 45363, Indonesia \\ ${ }^{4}$ Postgraduate Program, Universitas Islam Bandung, Jl. Tamansari No.1, Tamansari, Bandung 40116, Indonesia \\ ${ }^{5}$ Neurology Department, Faculty of Medicine, Universitas Padjadjaran, Jl. Raya Bandung Sumedang No. KM 21, Jatinangor 45363, Indonesia \\ ${ }^{6}$ Neurology Department, Dr. Hasan Sadikin General Hospital, Jl. Pasteur No.38, Bandung 40161, Indonesia \\ ${ }^{7}$ Department of Medicine and Biological Science, Gunma University Graduate School of Medicine, Maebashi, Gunma, Japan \\ ${ }^{8}$ Education and Research Support Center, Gunma University Graduate School of Medicine, Maebashi, Gunma, Japan \\ ${ }^{9}$ Study Program of Biotechnology, Post Graduate School, Universitas Padjadjaran, Jl. Raya Bandung Sumedang No.KM 21, Jatinangor 45363, Indonesia \\ ${ }^{*}$ Corresponding author. E-mail: rizky@unpad.ac.id
}

Received date: Feb 13, 2020; Revised date: Jul 29, 2020; Accepted date: Aug 3, 2020

\section{Abstract}

B ACKGROUND: Iron-overload cardiomyopathy (IOC) is a major comorbidity in patients with chronic repetitive blood transfusion due to myocardial iron uptake that facilitated by calcium channels. As cardiac compensatory mechanism to IOC, we hypothesized the cardiac calcium channels expression would be increased and involved in cardiomyopathy progressivity. This study was aimed to investigate the gene expression of calcium channels in the heart of the iron overload mice model.

METHODS: Mice were divided into three groups according to iron administration doses $0,0.1$, and $0.3 \mathrm{mg} /$ day. Systolic blood pressure (SBP), diastolic blood pressure (DBP), and mean arterial pressure (MAP) were measured for the representation of cardiovascular outcomes. The heart tissues were harvested. Further mRNA levels of L-type calcium channels (LTCCs) and T-type calcium channels (TTCCs) were examined using semi-quantitative PCR. The expressions of cardiac calcium channels and blood pressure among the three groups were compared.

RESULTS: The expressions of TTCCs in the two ironinjected groups were higher than the control group ( $p=0.018$ ). The expressions of LTCCs were not different ( $p=0.413$ ) among groups. SBP, DBP, and MAP of the ironinjected group were lower than the control group $(p=0.025$, $p=0.011$, and $p=0.008$, respectively).

CONCLUSION: Iron administration affects the expression of TTCCs but not the LTCCs, accompanied by decreasing of systolic and diastolic blood pressure.

KEYWORDS: cardiomyopathy, iron overload, L-type calcium channel, T-type calcium channel.

Indones Biomed J. 2020; 12(3): 261-6

\section{Introduction}

Repetitive blood transfusion in patients with a chronic hematological disease such as thalassemia will inevitably lead to iron overload. Iron overload becomes the major cause of comorbidity in thalassemia patients.(1,2) Excess iron accumulation in cardiac tissue may lead to iron overload cardiomyopathy.(3) Cardiomyopathy is defined as a heterogeneous group of myocardial diseases associated with mechanical and/or electrical dysfunction, which usually exhibit inappropriate ventricular hypertrophy or dilatation, 
due to a variety of etiologies. $(4,5)$ Meanwhile, iron overload cardiomyopathy (IOC) is described as the presence of systolic or diastolic cardiac dysfunction characterized by left ventricular (LV) remodeling with chamber dilatation and reduced LV ejection fraction due to high accumulation of iron. $(6,7)$ Clinically, IOC can be measured based on blood pressure declining and/or abnormal echocardiography parameters as well as the evidence of high-iron level parameters.(8) The prevalence of IOC is relatively high, and the spectrum of symptoms is varied. About $40 \%$ of $\beta$-thalassemia major patients who received prior chelation, had myocardial iron overload, and one of ten patients had a reduced LV ejection fraction.(9) Another life-threatening condition in iron overload patients such as arrhythmias, which may occur simultaneously with acute heart failure, leads to sudden cardiac death. $(10,11)$

The mechanism of IOC is mediated by reactive oxidative stress whereby iron accumulation at the cytoplasm becomes more available and fulfill component for Fenton Reaction, leading to the conversion of $\mathrm{Fe}^{2+}$ into $\mathrm{Fe}^{3+}$ produces free radical including the hydroxyl radicals in which leading to increase peroxidation and triggering cellular damage and antioxidants depletion. In the state of iron overload, transferrin is completely saturated, and the non-transferrin-bound iron (NTBI) is found in plasma. The NTBI is capable of entering the cardiomyocytes via L-type calcium channel (LTCC) and divalent metal transporter (DMT). NTBI enters cardiomyocytes via LTCC, competes with $\mathrm{Ca}^{2+}$ influx, and inhibits the entry of $\mathrm{Ca}^{2+}$. The higher concentration of $\mathrm{Fe}^{2+}$ associated with the decreased of $\mathrm{Ca}^{2+}$ influx as an implication of competitive interaction among them, contributing to the disturbance of myocardial contractility. On the other hand, iron-induced toxicity has progressively occurred. These conditions lead to cardiomyopathy. $(6,11,12)$

During cardiomyopathy, several compensatory mechanisms might be occurred, including neurohormonal activation and ventricular remodelling. $(13,14)$ Cardiac calcium channels, including LTCCs and TTCCs, are the important organelles that must be produced in suboptimal cardiac function. In cardiac contraction, LTCCs have a vital role as a voltage-gated ion channel. Normally, the expression of TTCCs occurs only in hearts during embryonic development. Then, TTCCs will disappear in adults. Pathologically, it can be found abundantly only in sinoatrial pacemaker cells and Purkinje fibers of many species in non-embryonic heart and are important for the maintenance of pacemaker activity. TTCCs can be reexpressed during pathological stress such as myocardial infarction, hypertrophy, and chronic renin-angiotensinaldosterone system (RAAS) stimulation. $(15,16)$ We hypothesized IOC expression of the ionic channel, including TTCCs, will be increased during the cardiac disturbance to compensate for the low function of LTCCs. Unfortunately, it potentially becomes a "new" pathway for NTBI to enter the cardiomyocytes, leads to more disturbance of cardiac tissue.(15)

The role of LTCCs and TTCCs in iron-induced cardiomyopathy has been investigated and proved in in vitro study.(17) Hence, the objective of this study was to investigate the effect of iron on the pathologic expression of LTCCs and TTCCs, in vivo.

\section{Methods}

The methods of this experimental study have complied with the ethical requirement for laboratory animal welfare principles (3R and $5 \mathrm{~F}$ ) and approved by The Ethics Committee Faculty of Medicine, Universitas Padjadjaran (No 43/UN6.C1.3.2/KEPK/PN/2017). The study was conducted at Animal Laboratory, Faculty of Medicine, Universitas Padjadjaran; Central Laboratory of Universitas Padjadjaran; and Gunma University, Japan, from April to July 2017.

\section{Animals, Grouping, and Injections}

The subjects of the study were 13 male Balb/c mice (Mus musculus) aged 10-12 weeks, with 20-30 grams in weight. Mice were purchased from the Department of Pharmacology, Faculty of Medicine, Universitas Padjadjaran. Mice were housed and maintained on a condition of 12/12 h light-dark cycle, adequate air circulation and had unrestricted access to water and standard chow. Mice were adapted for seven days before the experiment. Mice were distributed into three groups according to the dose of iron injection that consisted of four mice in intraperitoneal $\mathrm{NaCl}$ physiologic $0.2 \mathrm{~mL}$ injected (control), four mice in $0.1 \mathrm{mg} /$ day injected mice group, and five mice in $0.3 \mathrm{mg} /$ day injected mice group. Iron dextran was injected intraperitoneally each day for 18 days.

\section{Blood Pressure Measurement}

After 18 days and before organ collection, systolic blood pressure (SBP), diastolic blood pressure (DBP), as well as mean arterial pressure (MAP) were measured in conscious mice using a non-invasive computerized tail-cuff system.(18) 


\section{Organ Collection}

After 18 days, mice were sacrificed by cervical dislocation technique under inhaled anesthesia with isoflurane, then the apex of the heart was harvested. The harvested apex was kept in the Eppendorf tube and rapidly frozen and stored at $-80^{\circ} \mathrm{C}$ until the further processed.

RNA Isolation, Conventional PCR, and Quantitative Analysis

Total RNA was extracted and isolated from the frozen heart using TRIzol reagent (Catalog Number 15596-026, Life Technologies, Grand Island, NY, USA) according to the manufacture's protocol. The concentration of total RNA in each sample was quantified by spectrophotometric at 260 $\mathrm{nm}$. Semi-quantitative PCR was performed using the RTPCR Kit. The process was accorded to the manufacturer's protocol.(19) Primers were designed using Primer 3 software, for the genes CACNA1G for TTCCs, CACNA1C for LTCCs, and Glyceraldehyde 3-phosphate dehydrogenase (GAPDH) as the internal control (housekeeping gene). The sense sequences were as follows: TTCCs, forward: 5' TCATAGCCGTGCTGATGAAG 3', reverse: 3'AAGGGAGAAGCCTGAAGAGG 5'; and LTCCs, forward: 5' GCATCACAATCAGCAGG CTA3', reverse 3'ACGGGGTTCTACAGGCTTTT5'; as well as GAPDH: forward: 5'CAACTCCCACTCTTCCACCT3', reverse: 3' GAGTTGGGATAGGGCCTCTC 5'. The expression levels of the target gene were normalized to GAPDH mRNA levels. The gel electrophoresis signals of the PCR products were quantified using Image J Software (National Institute of Health, Bethesda, Maryland).

\section{Statistical Analysis}

All statistics were managed and analyzed using SPSS 20.0 software (IBM, Chicago, USA). Results of numerical data were presented as the mean \pm standard error of the mean $(m e a n \pm S E M)$. One-way MANOVA was used to analyze data, and post hoc of Bonferroni's multiple comparison tests were used to evaluate the differences of the expression TTCC and LTCC, as well as SBP, DBP, and MAP among groups. In order to compare the means of TTCC expression and SBP between the two-experimental groups versus the control group, an independent T-test was performed. Kruskal-Wallis were used to compare the heart weight between groups. For all analyses, $\alpha$ was set a priori at 0.05 .

\section{Results}

\section{Measurement of Cardiac Weight and Heart-Body Weight Ratio}

The mean of the heart weight was $0.126 \pm 0.005$ grams in the control group, $0.116 \pm 0.004$ grams in the $0.1 \mathrm{mg}$ /day iron administration group, and $0.126 \pm 0.009$ grams in the $0.3 \mathrm{mg} /$ day iron administration group. There was no difference in heart weight among groups $(p=0.190)$.

The measurement of the heart-body weight ratio showed that the ratio $0.0034 \pm 0.0001$ in the control group, $0.0035 \pm 0.0001$ in the $0.1 \mathrm{mg} /$ day iron administration group, and $0.0037 \pm 0.0002$ in the $0.3 \mathrm{mg} /$ day iron administration group. The heart weight-body weight ratio of the mice was also showed no difference among groups $(p=0.454)$.

\section{TTCCs and LTCCs Expression}

Figure 1 and 2 depict the PCR result of TTCC and LTCC, respectively. After quantified using Image $J$ and normalized against GAPDH mRNA levels, the TTCC - GAPDH gene ratio was obtained. The mean of the ratio was $1.000 \pm 0.157$ in the control group, $1.934 \pm 0.297$ in the $0.1 \mathrm{mg} /$ day iron administration group, and $1.903 \pm 0.161$ in the $0.3 \mathrm{mg}$ /day iron administration group, indicating at least one group has significant difference in the average of TTCC expression ( $p=0.018$ ) (Figure 3). Bonferroni's post hoc test showed that the expression of TTCC in the $0.1 \mathrm{mg} /$ day and $0.3 \mathrm{mg} /$ day iron administration groups were higher than the control group, $p=0.037$ and $p=0.033$, respectively. Meanwhile, there was no significant difference in the TTCC expression between the $0.1 \mathrm{mg} / \mathrm{day}$ and $0.3 \mathrm{mg} / \mathrm{day}$ iron administration groups $(p=1.000)$. In addition, the expression of TTCC in the two-experimental groups was higher than in the

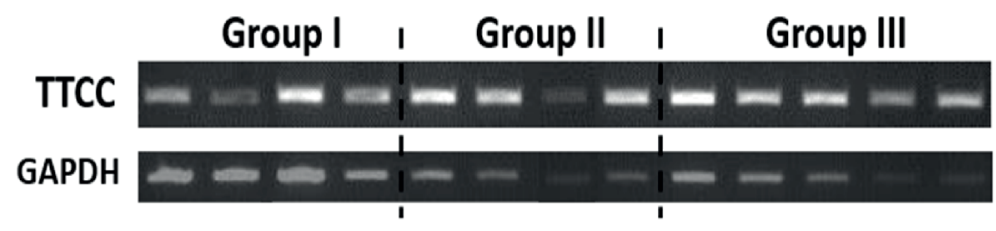

Figure 1. Comparison of semi-quantitative PCR for Cardiac TTCCs gene with the GAPDH gene as an internal control in mice with iron administration $\mathbf{0 , 0 . 1}$ and $0.3 \mathrm{mg} /$ day (Group I, II and III, respectively). GAPDH: Glyceraldehyde 3-phosphate dehydrogenase; TTCCs: T-type calcium channels. 


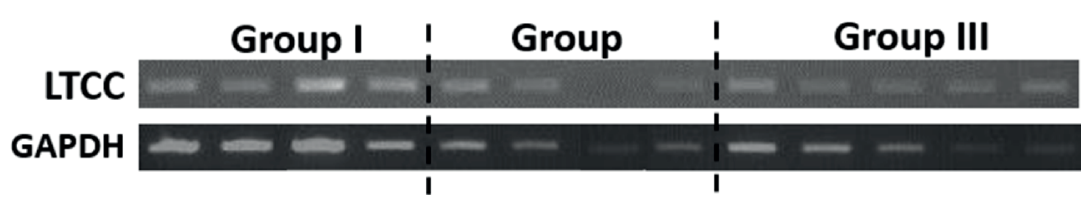

Figure 2. Comparison of semi-quantitative PCR for Cardiac LTCCs gene with the GAPDH gene as an internal control in mice with iron administration 0, 0.1 and $\mathbf{0 . 3} \mathrm{mg} /$ day (Group I, II and III, respectively). GAPDH: Glyceraldehyde 3-phosphate dehydrogenase; LTCCs: L-type calcium channels.

control groups $(1.000 \pm 0.157$ vs. $1.917 \pm 0.444$, respectively, $p=0.004$ )

The LTCC-GAPDH ratio was $1.000 \pm 0.103$ in the control group, $1.259 \pm 0.172$ in the $0.1 \mathrm{mg} /$ day iron administration group, and $1.203 \pm 0.139$ in the $0.3 \mathrm{mg}$ /day iron administration group. There was no significant difference in the LTCC expression on the control group compared to the experimental groups $(p=0.413$ ) (Figure 4 ).

\section{Comparison of Blood Pressure among Groups}

The means of SBP, DBP, and MAP were shown in Table 1. The result of SBP was indicating at least one group has a significant difference in averages, $p=0.025$. Bonferroni's post hoc test showed that SBP of the $0.3 \mathrm{mg}$ /day iron administration group was significantly lower than the SBP of the control group, $p=0.032$. Meanwhile, the result of DBP was indicating that at least one group has a significant difference in averages, $p=0.011$. DBP of the $0.3 \mathrm{mg} /$ day iron administration group was significantly lower than the control group ( $p=0.013$ ). The MAP of that $0.3 \mathrm{mg}$ /day iron administration group was significantly lower than the control group ( $p=0.009$ ). In addition, a significant mean difference of the SBP in the control group to the two-experimental

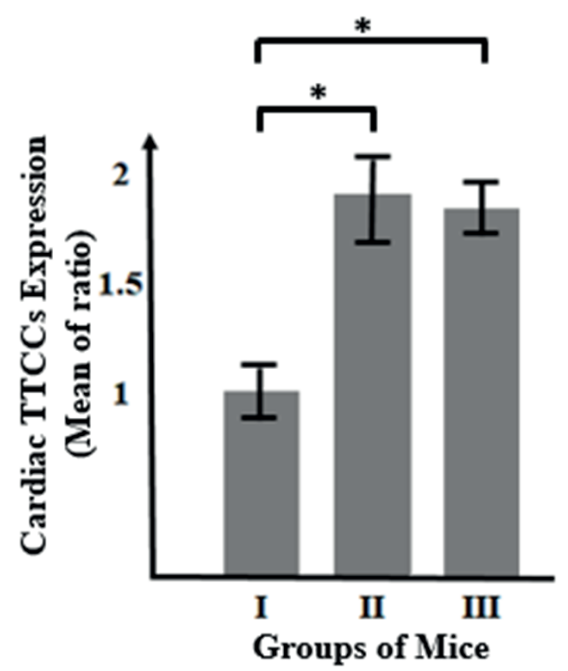

Figure 3. Comparison of cardiac TTCCs expression in mice with iron administration $0,0.1$ and $0.3 \mathrm{mg} /$ day (Group I, II and III, respectively). $* p<0.05$
(Group II and III) groups was confirmed by Independent Samples T-Test $(85.60 \pm 16.22 \mathrm{mmHg}$ and $57.50 \pm 15.96$ $\mathrm{mmHg}$, respectively, $p=0.013$ )

\section{Discussion}

Our study revealed that iron administration affects the calcium channels, specifically the TTCCs, but not the LTCCs. Moreover, the cardiovascular outcome, that measured using blood pressure was also affected. Regardless of the doses, the iron injected mice had more expression of TTCCs. On the other hand, only high-dose of iron injection group that had significantly lower blood pressure. As the previous study indicated, the relationship between cardiac channels and ventricular performance (20), the decreased SBP, DBP, and MAP in our study can reflect that alteration of calcium channel expression was accompanied by alteration of blood pressure.

During an iron overload condition, NTBI flows into the cells by diffusion and generates free iron. $(6,15)$ By the Fenton - reaction mechanism and compete $\mathrm{Ca}^{2+}$ movement in - out of the cells, iron overload damages the structure

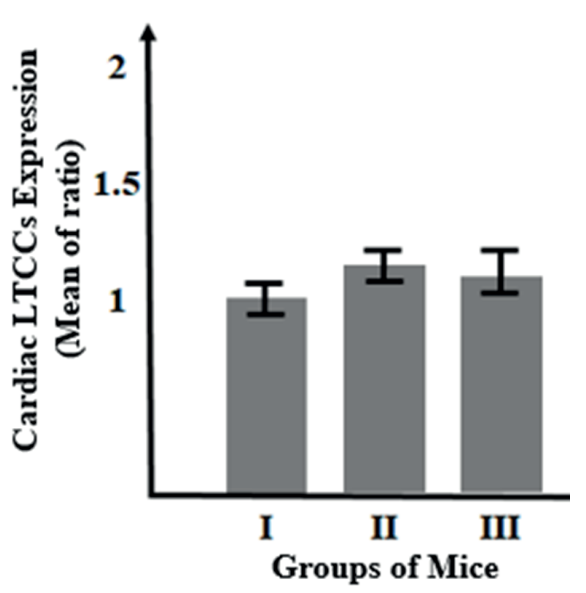

Figure 4. Comparison of cardiac LTCCs expression in mice with iron administration $0,0.1$ and $0.3 \mathrm{mg} /$ day (Group I, II and III, respectively). 
Table 1. Comparison of blood pressure between groups.

\begin{tabular}{llcc}
\hline \multicolumn{1}{c}{ Blood Pressure } & \multicolumn{1}{c}{$\begin{array}{c}\text { Groups of Iron } \\
\text { Administration }\end{array}$} & $\begin{array}{c}\text { Mean } \pm \text { SEM } \\
(\mathbf{m m H g})\end{array}$ & $\boldsymbol{p}$-value \\
\hline Systolic & Group I $(0 \mathrm{mg} / \mathrm{day})^{*}$ & $121.00 \pm 9.69$ & 0.025 \\
& Group II $(0.1 \mathrm{mg} /$ day $)$ & $93.50 \pm 9.06$ & \\
& Group III $0.3 \mathrm{mg} /$ day* & $88.60 \pm 3.67$ & \\
\hline Diastolic & Group I $(0 \mathrm{mg} / \text { day })^{* *}$ & $93.25 \pm 6.80$ & 0.011 \\
& Group II $(0.1 \mathrm{mg} /$ day $)$ & $69.50 \pm 5.23$ & \\
& Group III $(0.3 \mathrm{mg} / \text { day })^{* *}$ & $63.40 \pm 5.38$ & \\
\hline Mean arterial pressure & Group I $(0 \mathrm{mg} / \text { day })^{* * *}$ & $102.50 \pm 7.61$ & 0.008 \\
& Group II $(0.1 \mathrm{mg} /$ day $)$ & $77.33 \pm 5.79$ & \\
& Group III $(0.3 \mathrm{mg} / \text { day })^{* * *}$ & $71.80 \pm 3.71$ & \\
\hline
\end{tabular}

*Significantly different, post hoc analysis showed $p=0.032$.

**Significantly different, post hoc analysis showed $p=0.013$.

$* * *$ Significantly different, post hoc analysis showed $p=0.009$.

and disrupts the electrophysiology processes of the heart. These mechanisms are responsible in the pathogenesis of iron overload cardiomyopathy. $(6,21)$

Our study proved the increased cardiac channel expression in IOC. Generally, in the condition of suboptimal cardiac function, calcium channels are increasing in expression. It might be due to a compensating mechanism to improve cardiac capability, both electrically and mechanically. Unfortunately, the higher number of calcium channel expression, the more progressive cardiomyopathy probably occurs. $(6,12)$

In our study, the condition of iron administration increases the expression of cardiac TTCCs, but did not increase the LTCC one. Our study was consistent with previous study results, especially in the role of TTCCs during iron overload cardiomyopathy. $(3,17)$ TTCCs that normally not expressed in myocardium tissue, in the state of ischemic and other pathologic conditions, might be expressed in sub-optimum cardiac function. Probably, sub-optimum cardiac function is corresponding with the failure of LTCCs compensation. The expression of calcium channel might be altered under the regulation by neurohormonal factors, such as angiotensin II (AT-II), growth hormone $(\mathrm{GH}), 17 \beta$-estradiol, insulin-like growth factor (IGF), and alpha-adrenergic stimuli. Several transcription factors such as neurorestrictive silencer factor (NRSF) and Csx/Nkx2.5 also regulate the calcium channel expression.(15,21-23) Some studies demonstrated that TTCC re-expression in the heart of iron overload thalassaemic mice could be detected by real-time PCR and microarray, as well as were proving the role of TTCCs as a transporter for iron. $(17,24)$
In the present study, there was indicating a decrease in systolic and diastolic function among the iron administered group. The decrease of systolic and cardiac function in dose iron administered, which is $0.3 \mathrm{mg} /$ day, but not in $0.1 \mathrm{mg}$ / day injected group, also indicates the progressivity of IOC is dose-dependent. However, TTCCs that also increased in $0.1 \mathrm{mg} /$ day injected-group also reflects the structural impairment on iron overload condition. Suggestively, the increasing number of calcium channels failed to compensate for the progressivity of cardiomyopathy. The failure of compensation by increased calcium channel expression, in this case, suggestively due to the existence of $\mathrm{Fe}^{2+}$, that compete the $\mathrm{Ca}^{2+}$ leads to systolic and diastolic function alterations.(12) Although the expression of calcium channel increase, inhibition of $\mathrm{Ca}^{2+}$ influx still occurs and cardiac iron toxicity becomes worsening as long as transferrin saturation is still high. $(24,25)$ However, TTCC blocker provided all benefits including attenuating iron deposit in both the heart and liver, reduced oxidative stress, and decreased mortality as well as improves cardiovascular function in ironoverloaded mice.(24) On the other hand, IOC disrupt the calcium channels normal activity and causing bradycardia, slowing of electrical conduction, and atrial fibrillation as seen in patients with iron overload, in vivo.(26)

As limitations, this study did not observe the expression of cardiac LTCCs and TTCCs during iron overload conditions, as well as the role of these channels in the progressivity of iron-overload cardiomyopathy. Our study also did not provide the actual data about the confirmation for cardiomyopathy development in mice using echocardiography to find out the cardiac output and chamber dilation. However, the findings of decreased SBP 
and DBP in our study can reflect the effect of iron overload on cardiovascular, particularly blood pressure. Further study that examines objective cardiomyopathy biomarkers such as expression of laminin a/c (LMNA), troponin T and cardiac actin is needed.(27) On the other hand, the alteration function of cardiac electrical conduction was not evaluated. Further in vivo study, which provides iron overload models, and cardiomyopathy observation, then the association of them, are needed.

\section{Conclusion}

In summary, iron administration increases the expression of cardiac TTCCs but not the LTCCs. It is accompanied by decreasing of systolic and diastolic blood pressure in the iron administered group. Suggestively, decrease function of the heart might occur.

\section{Acknowledgements}

This study was funded by the Academic Leadership Grant of Universitas Padjadjaran.

\section{References}

1. Borgna-Pignatti C, Gamberini MR. Complications of thalassemia major and their treatment. Expert Rev Hematol. 2011; 4: 353-66.

2. Kremastinos DT, Farmakis D, Aessopos A, Hahalis G, Hamodraka E, Tsiapras D, et al. Beta-thalassemia cardiomyopathy: history, present considerations, and future perspectives. Circ Heart Fail. 2010; 3: 451-8.

3. Moon SN, Han JW, Hwang HS, Kim MJ, Lee SJ, Lee JY, et al Establishment of secondary iron overloaded mouse model: evaluation of cardiac function and analysis according to iron concentration. Pediatr Cardiol. 2011; 32: 947-52.

4. Eugene B. Cardiomyopathies. Circ Res. 2017; 121: 711-21

5. Brieler J, Breeden MA, Tucker J. Cardiomyopathy: an overview. Am Fam Physician. 2017; 96: 640-6.

6. Cheng CF, Lian WS. Prooxidant mechanisms in iron overload cardiomyopathy. Biomed Res Int. 2013; 2013: 740573. doi: 10.1155/2013/740573

7. Kremastinos DT, Farmakis D. Iron overload cardiomyopathy in clinical practice. Circulation. 2011; 124: 2253-63.

8. Bornaun H, Dedeoglu R, Oztarhan K, Dedeoglu S, Erfidan E, Gundogdu $\mathrm{M}$, et al. Detection of early right ventricular dysfunction in young patients with thalassemia major using tissue Doppler imaging. Iran J Pediatr. 2016; 26(3): e5808. doi: 10.5812/ ijp.5808.

9. Aydinok Y, Porter JB, Piga A, Elalfy M, El-Beshlawy A, Kilinc Y, et al. Prevalence and distribution of iron overload in patients with transfusion-dependent anemias differs across geographic regions: results from the CORDELIA study. Eur J Haematol. 2015; 95: 244 53.

10. Gulati V, Harikrishnan P, Palaniswamy C, Aronow WS, Jain D, Frishman WH. Cardiac involvement in hemochromatosis. Cardiol Rev. 2014; 22: 56-68.

11. Shizukuda Y, Rosing DR. Iron overload and arrhythmias: Influence of confounding factors. J Arrhythmia. 2019; 35: 575-83.

12. Lopin KV, Gray IP, Obejero-Paz CA, Thévenod F, Jones SW. Fe2+ block and permeation of CaV3.1 $(\alpha 1 \mathrm{G})$ T-type calcium channels: candidate mechanism for non-transferrin-mediated $\mathrm{Fe} 2+$ influx. Mol Pharmacol. 2012; 82: 1194-204.

13. Kemp CD, Conte JV. The pathophysiology of heart failure. Cardiovasc Pathol. 2012; 21: 365-71.

14. Harvey PA, Leinwand LA. The cell biology of disease: cellular mechanisms of cardiomyopathy. J Cell Biol. 2011; 194: 355-65.

15. Chattipakorn N, Kumfu S, Fucharoen S, Chattipakorn S. Calcium channels and iron uptake into the heart. World J Cardiol. 2011; 3: 215-8

16. Ono K, Iijima T. Cardiac T-type $\mathrm{Ca}(2+)$ channels in the heart. J Mol Cell Cardiol. 2010; 48: 65-70.

17. Kumfu S, Chattipakorn S, Srichairatanakool S, Settakorn J, Fucharoen $\mathrm{S}$, Chattipakorn N. T-type calcium channel as a portal of iron uptake into cardiomyocytes of beta-thalassemic mice. Eur J Haematol. 2011; 86: 156-66

18. Zhao X, Ho D, Gao S, Hong C, Vatner DE, Vatner SF. Arterial pressure monitoring in mice. Curr Protoc Mouse Biol. 2011; 1: 10522.

19. Lawyer FC, Stoffel S, Saiki RK, Myambo K, Drummond R, Gelfand DH. Isolation, characterization, and expression in Escherichia coli of the DNA polymerase gene from Thermus aquaticus. J Biol Chem. 1989; 264: 6427-37.

20. Tabima DM, Hacker TA, Chesler NC. Measuring right ventricular function in the normal and hypertensive mouse hearts using admittance-derived pressure-volume loops. Am J Physiol Heart Circ Physiol. 2010; 299: H2069-75.

21. Gujja P, Rosing DR, Tripodi DJ, Shizukuda Y. Iron overload cardiomyopathy: better understanding of an increasing disorder. J Am Coll Cardiol. 2010; 56: 1001-12.

22. Das SK, Wang W, Zhabyeyev P, Basu R, McLean B, Fan D, et al. Iron-overload injury and cardiomyopathy in acquired and genetic models is attenuated by resveratrol therapy. Sci Rep. 2015; 5(1): 18132. doi: 10.1038/srep18132.

23. Cribbs L. T-type calcium channel expression and function in the diseased heart. Channels (Austin). 2010; 4: 447-52.

24. Kumfu S, Chattipakorn S, Chinda K, Fucharoen S, Chattipakorn N. T-type calcium channel blockade improves survival and cardiovascular function in thalassemic mice. Eur J Haematol. 2012; 88: $535-48$

25. Komukai M, Tsutsumi T, Ebado M, Takeyama Y. Effect of an L- and T-type calcium channel blocker on 24-hour systolic blood pressure and heart rate in hypertensive patients. Korean Circ J. 2012; 42: 231-8

26. Rose RA, Sellan M, Simpson JA, Izaddoustdar F, Cifelli C, Panama $\mathrm{BK}$, et al. Iron overload decreases CaV1.3-dependent L-type $\mathrm{Ca} 2+$ currents leading to bradycardia, altered electrical conduction, and atrial fibrillation. Circ Arrhythm Electrophysiol. 2011; 4: $733-42$.

27. Sequeira V, Nijenkamp LLAM, Regan JA, van der Velden J. The physiological role of cardiac cytoskeleton and its alterations in heart failure. Biochim Biophys Acta - Biomembr. 2014; 1838: 700-22. 